\title{
Die vielen Leben des Artikels 47c KVG
}

\section{Yvonne Gilli}

Dr. med., Präsidentin FMH

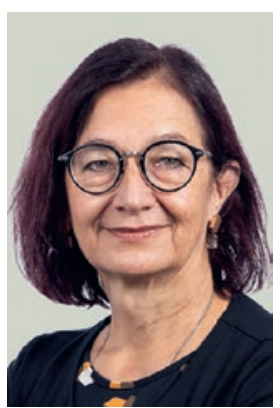

Wer das politische Geschehen aufmerksam verfolgt, erlebt immer wieder Déjà-vus. Im Gegensatz zum echten Déjà-vu handelt es sich dabei jedoch meistens nicht um eine Erinnerungstäuschung. Häufig ist die Erinnerung, dass ein politisches Vorhaben bereits mehrfach diskutiert (und verworfen) wurde, völlig korrekt. Dies ist auch der Fall, wenn in diesen Tagen das Parlament die Ergänzung eines Artikels 47 c im KVG diskutiert, ein Vorhaben von enormer Tragweite für unser Gesundheitswesen. Der Artikel fordert «Regeln zur Korrektur bei ungerechtfertigten Erhöhungen der Mengen und der Kosten». Was erstmal unverdächtig klingt, setzt de facto die Festlegung einer Kostenobergrenze voraus, bis zu der Patientenbehandlungen als "gerechtfertigt» gelten. Wird diese Grenze überschritten, drohen Ärzten und Ärztinnen finanzielle Sanktionen. Wir sollen also genötigt werden, eine vorab definierte Kostengrenze nicht zu überschreiten - unabhängig davon, was unsere Patienten und Patientinnen brauchen.

Wem diese Forderungen seltsam bekannt vorkommen, hat guten Grund dazu: Bereits im Jahr 2017 forderte die teilweise wortgleiche Kommissionsinitiative 17.402 ebenfalls eine solche Budgetierung. Die Gesundheitskommission des Nationalrats SGK-N warb im Mai 2018

\section{Häufig ist die Erinnerung, dass ein politisches Vorhaben bereits mehrfach diskutiert (und verworfen) wurde, völlig korrekt.}

mit Verweis auf die Gesundheitskosten eindringlich für diese Initiative, die den Bundesrat «in seinen Bestrebungen, Kostendämpfungsmassnahmen durchzusetzen, unterstützen» sollte [1]. Nach einer inhaltlichen Diskussion u.a. über Rationierung als mögliche Folge von Kostenobergrenzen kam der Nationalrat jedoch zu einer anderen Auffassung und versenkte die Initiative mit 97 zu 91 Stimmen [1].

Mit dieser parlamentarischen Niederlage wären die «Massnahmen zur Steuerung der Kosten und Leistungen» Geschichte gewesen, hätte ihnen nicht das Eidgenössische Departement des Innern (EDI) ein zweites Leben beschert: Das im Herbst 2018 in die Vernehm- lassung geschickte erste Kostendämpfungspaket umfasste acht Massnahmen, die aus dem Expertenbericht abgeleitet waren - und den auf Wunsch des EDI eingebrachten Artikel 47c. [2] Im Windschatten des Expertenberichts wurde so die abgelehnte Initiative 17.402 erneut vorgelegt und fand ihren Weg in das vom Bundesrat 2019 verabschiedete Massnahmenpaket.

Massive Eingriffe in unser Gesundheitswesen sollten nicht durch Penetranz und Ränkespiele mit hauchdünnen Mehrheiten durchgesetzt werden.

Im Parlament folgten viele Abstimmungen, die nicht knapper hätten ausfallen können. So entschied zunächst die Gesundheitskommission des Nationalrats im August 2020 mit 12:11 Stimmen, den Artikel 47c nicht zu streichen, wenige Monate später entschied der Nationalrat hingegen mit 91:90 Stimmen, den Artikel zu streichen. Ein Jahr darauf, im Oktober 2021, entschied die ständerätliche Gesundheitskommission mit 7:6 Stimmen wiederum, den Artikel nicht zu streichen, und wiederum wenige Monate später, im Dezember 2021, beschloss der Ständerat mit 21:20 Stimmen, den Artikel zu streichen. Mit den Streichungen durch National- und Ständerat schien Ende 2021 dann auch das zweite Leben des Artikels $47 \mathrm{c}$ beendet.

Doch die üblichen Regeln scheinen beim Artikel 47c nicht zu gelten: Im Januar 2022 verhalfen Rückkommensanträge in beiden Gesundheitskommissionen dem Artikel 47c zu seinem dritten Leben. Dass auch hier wieder das EDI im Hintergrund mitwirkte, kann nur vermutet werden. Im neu lancierten Spiel der knappen Entscheide hat die SGK-N den Artikel 47c zuletzt mit Stichentscheid ihres Präsidenten wieder gestrichen und es ist zu hoffen, dass der Nationalrat diesem Entscheid am 28. Februar folgen wird. Massive Eingriffe in unser Gesundheitswesen, wie sie der Artikel 47c impliziert, sollten nicht durch Penetranz und Ränkespiele mit hauchdünnen Mehrheiten durchgesetzt werden. Zumal das nächste Déjà-vu bald folgen wird: Mit dem indirekten Gegenvorschlag einer «Zielvorgabe» werden wir sehr bald wieder über Budgetierung diskutieren müssen. 